\title{
Correction: Healthcare barriers, what about older age? A comment on Malik-Soni et al.
}

\author{
David Mason
}

(c) The Author(s) 2021

Pediatric Research (2022) 91:1301; https://doi.org/10.1038/s41390-021-01652-x

Correction to: Pediatric Research https://doi.org/10.1038/s41390021-01596-2, published online 09 June 2021

The reference list for this Commentary is incorrect from ref. ${ }^{11}$ onwards. The in-text citations are not affected. The original article has been corrected. The correct references are:

11. Shattuck, P. T., Wagner, M., Narendorf, S., Sterzing, P. \& Hensley, M. Post-high school service use among young adults with an autism spectrum disorder. Arch. Pediatr. Adolesc. Med. 165, 141-146 (2011).

12. Hillman, H. Child-centered play therapy as an intervention for children with autism: a literature review. Int. J. Play Ther. 27, 198 (2018).

13. Fuller, E. A. \& Kaiser, A. P. The effects of early intervention on social communication outcomes for children with autism spectrum disorder: a meta-analysis. J. Autism Dev. Disord. 50, 1-18 (2019).

14. Vivanti, G. et al. Implementing and evaluating early intervention for children with autism: Where are the gaps and what should we do? Autism Res. 11, 16-23 (2018).

15. Vogan, V., Lake, J. K., Tint, A., Weiss, J. A. \& Lunsky, Y. Tracking health care service use and the experiences of adults with autism spectrum disorder without intellectual disability: a longitudinal study of service rates, barriers and satisfaction. Disabil. Health J. 10, 264-270 (2017).

16. Saqr, Y. et al. Addressing medical needs of adolescents and adults with autism spectrum disorders in a primary care setting. Autism 22, 51-61 (2018).

17. Nicolaidis, C. et al. "Respect the way I need to communicate with you": healthcare experiences of adults on the autism spectrum. Autism 19, 824-831 (2015).

18. Hull, L. et al. "Putting on my best normal": social camouflaging in adults with autism spectrum conditions. J. Autism Dev. Disord. 47, 2519-2534 (2017).

19. Lai, M. C. et al. Quantifying and exploring camouflaging in men and women with autism. Autism 21, 690-702 (2017).
20. Livingston, L. A. et al. Good social skills despite poor theory of mind: exploring compensation in autism spectrum disorder. $J$. Child Psychol. Psychiatry 60, 102-110 (2019).

21. Skinner, C. et al. Autistic disorder: a 20 year chronicle. J. Autism Dev. Disord. 51, 677-684 (2021).

22. Howlin, P., Moss, P., Savage, S. \& Rutter, M. Social outcomes in mid-to later adulthood among individuals diagnosed with autism and average nonverbal IQ as children. J. Am. Acad. Child Adolesc. Psychiatry 52, 572-581 (2013).

23. Anderson, K. A., Sosnowy, C., Kuo, A. A. \& Shattuck, P. T. Transition of individuals with autism to adulthood: a review of qualitative studies. Pediatrics 141, S318-S327 (2018).

24. Crompton, C. J., Michael, C., Dawson, M. \& Fletcher-Watson, S. Residential care for older autistic adults: insights from three multiexpert summits. Autism Adulthood 2, 121-127 (2020).

25. Robbins, I. et al. Explaining the barriers to and tensions in delivering effective healthcare in UK care homes: a qualitative study. BMJ Open 3, e003178 (2013).

Publisher's note Springer Nature remains neutral with regard to jurisdictional claims in published maps and institutional affiliations.

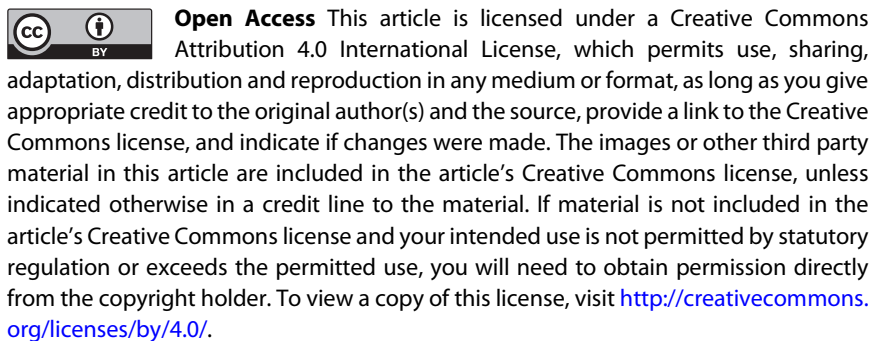

(c) The Author(s) 2021 